\title{
Dev Aksiller Kavernöz Hemanjiyomlu Bir Yenidoğan
}

A Neonate with A Giant Cavernous Hemangioma in the Axilla

\section{Gökmen KURT ${ }^{1}$, Dolunay ALVER ${ }^{1}$, Ceyhan ŞAHİN ${ }^{1}$, Ayşenur Cerrah CELAYİR ${ }^{1}$}

1. Zeynep Kamil Kadın ve Çocuk Hastalıkları Eğitim ve Araştırma Hastanesi, İstanbul, Türkiye

\section{$\ddot{O Z Z E T}$}

Giriş ve Amaç: Hemanjiyomlar kan damarlarının iyi huylu proliferasyonlarıdır. Kafa içi, karın ve cilt gibi birçok lokalizasyonda olabildikleri gibi, Kasabach Meritt, Klippel Trenaunay Weber Sendromu gibi sendromlarla beraber de olabilirler. Dev hemanjiyomların postnatal erken dönemde opere edilerek olasi geç komplikasyonların önüne geçilebileceğini vurgulanması amacıla olgumuz sunulmuştur.

Olgu Sunumu: 26 günlük erkek olgu să̆ aksiller bölgede $10 \times 10 \mathrm{~cm}$ dişarıya doğru büyüyen kitle nedeniyle yatırldı. Kitlenin üzerinde kilcal hemanjiyomlarin gözlenmesi nedeniyle hemanjiyom oldugu düşünüldü. Trombositopeni izlenmeyen hastada kranial ve batın ultrasonografisi (US) normal bulundu. Ekokardiografik incelemede ASD, ince PDA ve periferik pulmoner stenoz saptandi. Manyetik rezonans görüntüleme (MRG) incelemede; sağ aksiller arterden geniş bir pedikülle beslenen, sağ hemitoraks duvarl posterolaterali ve aksiller fossay dolduran ve toraks duvarina invazyon izlenmeyen yaklaşık $12 \mathrm{~cm}$ boyutunda damarsal yapıdan zengin hemanjiyom olduğu düşünülen kitle izlendi. Ameliyat sırasında kitle pedikülünün $11 \mathrm{~mm}$ çapında çok geniş olduğu görüldü ve kitle total eksize edildi. Ameliyat sonrası beşinci gün sorunsuz olan taburcu edilen hastanın birinci yıl kontrolünde nüks saptanmadi.

Sonuç: Hemanjiyomlar ilk 3 yl içinde kendiliğinden regrese olabileceği bilindiği için klinik olarak takip edilmektedir. Ancak dev kavernöz hemanjiyomlar, trombositopeni ve kanamaya eğilimleri yanisıra kardiak yetersizliğe neden olabilecekleri için bu olguların erken postnatal dönemde ameliyat öncesi hazırlıklarının tamamlanmasi ve takiben opere edilmesi; kozmetik iyi sonuç ve olası komplikasyonları önleme açısından gereklidir.

Anahtar Kelimeler: hemanjiyom, kavernöz hemanjiyom, Kasabach Merrith Sendromu, vasküler malformasyonlar

\footnotetext{
İletişim Bilgileri:

Sorumlu Yazar: Ayşenur CERRAH CELAYIR

Yazışma Adresi: Zeynep Kamil Kadın ve Çocuk Hast. Eğitim ve Araştırma Hastanesi, İstanbul, Türkiye

E-Posta: celayiraysenur@gmail.com

Tel: 0(532) 3265669

Makalenin Geliş Tarihi: 20.08.2014

Makalenin Kabul Tarihi: 13.08.2015

DOI: http://dx.doi.org/10.16948/zktb.01165
}

\section{ABSTRACT}

Introduction and Aim: Hemangiomas are benign proliferative lesions of the blood vessels. The hemangiomas may be present in different locations such as skin, abdomen or intracranial. They may accompany syndromes as Kasabach-Meritt and Klippel-Trenaunay-Weber. The aim of this study is to emphasize the importance of early surgical intervention during the early postnatal period in order to prevent the late complications of giant hemangiomas.

Case Report: A 26-days-old boy newborn was admitted to our clinic presented with a protruded mass with capillary proliferations on it, located in the right axilla, with dimensions of $10 \times 10 \mathrm{~cm}$. Presumptive diagnosis was a hemangioma because of the vascular appearance of the mass. He had not thrombocytopenia, and any pathology was found in abdominal and intracranial ultrasonography (US). Echocardiography was revealed ASD, and PDA, and peripheral pulmonary stenosis. In magnetic resonance imaging (MRI) of the mass and thorax, a $12 \mathrm{~cm}$ diameter mass on posterolateral of the right hemi-thorax wall, filling the right axillary fossa, supplied by a thick branch from axillary artery, showing no invasion to the thoracic wall was observed. The mass was totally excised with open surgery. The postoperative period was uneventful and the patient was discharged on the fifth postoperative day. No recurrence was detected one year later on follow-up.

Conclusion: Hemangiomas may regress spontaneously within the first 3 years in the clinical follow-up. Since the giant cavernous hemangiomas may cause cardiac failure besides causing thrombocytopenia and blood loss due to their tendency to bleeding, surgical intervention in the early postnatal period following rapid completion of preoperative preparations is mandatory to prevent possible complications and to achieve good cosmetic results.

Keywords: hemangiomas, cavernous hemangiomas, Kasabach Merrith Syndrome, vascular malformations 


\section{GİRİŞ}

S1k görülen doğum defektleri arasında yer alan vasküler malformasyonlar, gerek anatomik lokalizasyon gerekse klinik prezentasyonları açısından çok çeşitlilik gösterirler (1-5). Yüzeyel kapiller hemanjiyomlar da dahil edildiğinde sıklığı yenidoğan döneminde $\% 1.1-2.6 ; 1$ yaş civarında \%10.1'dir $(4,5)$. Düșük doğum ağırlıklı ve özellikle 1000 gram altı bebeklerde ise insidans \%12-23'dür (1).

Hemanjiyomlar bazen Kasabach Meritt Sendromu ve Klippel Trenaunay Weber Sendromu gibi hastalıkların bir komponenti olabildiği gibi, izole vakalar olarak da görülebilirler. Yerleşim yerleri açısından çoğunluğu yüzeyeldir. Bunların \%60'1 baș boyun, \%25'i gövde ve $\% 15$ 'i ekstremitelerde bulunmakla beraber \%20 olguda multiple hemanjiyomlar olabilir (1).

Tedavi lezyonun tipine anatomik lokalizasyonuna boyutuna ve klinik prezentasyonuna göre planlanır. İzlem, kompresyon, sklerozan madde enjeksiyonu, embolizasyon ve cerrahi yöntemler tedavi seçenekleri arasındadır (1-5). Bu yazının amacı, dev hemanjiyomların postnatal erken dönemde opere edilerek olası geç komplikasyonların önüne geçilebileceğini vurgulamaktır.

\section{OLGU SUNUMU}

26 günlük erkek yenidoğan, doğduğu andan itibaren mevcut olan sirtta doğru yayılan sağ koltuk altında şişlik nedeni ile kliniğimize başvurdu. Fizik değerlendirmede sağ aksilla posteriorundan başlayıp sağ skapular bölgeye ilerleyen üzeri telanjektazik görünümlü cilt ile kaplı, 10x10 cm ebadında yumuşak kıvamlı kitle mevcuttu (Resim 1). Kitle üzerinde tril veya üfürüm yoktu.

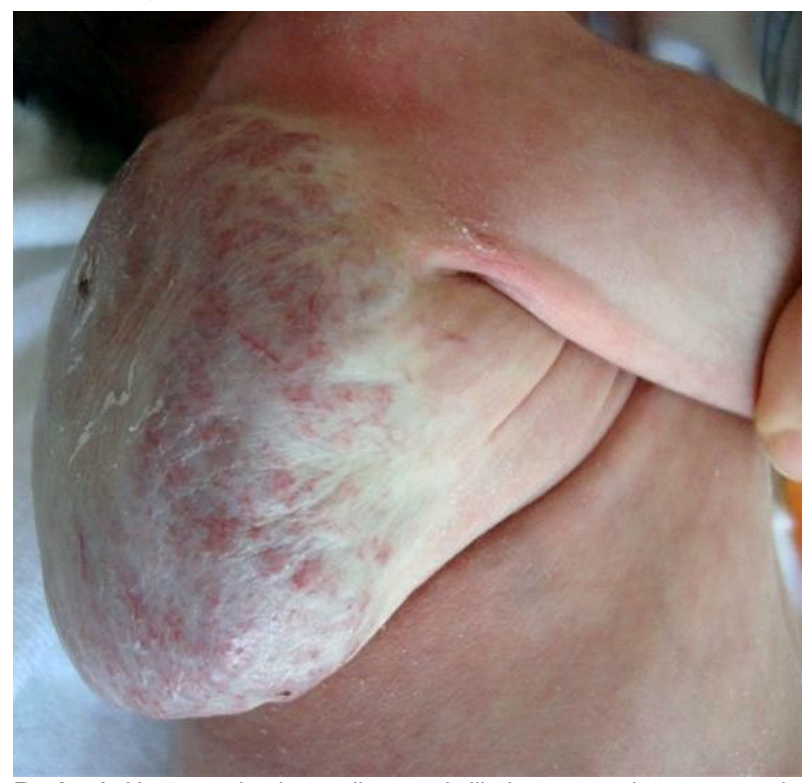

Resim 1: Hastanın dev hemanjiyomu aksilladan sırtına doğru uzanmak tadır.
Laboratuvar değerlendirmelerde trombositopeni, anemi izlenmedi. Ek anomaliler aç1sindan yapılan preoperatif ekokardiyografik değerlendirmede ASD, ince PDA ve periferik tipte pulmoner stenoz saptandi. Batın ve kranial US incelemeleri olağan idi. MRG'de toraks içine uzanım göstemeyen ancak aksiller fossayı tamamen dolduran, aksiler arter ve venden geniş çaplı vasküler pedikül alan hemanjiyomatöz kitle izlendi (Resim 2-3).
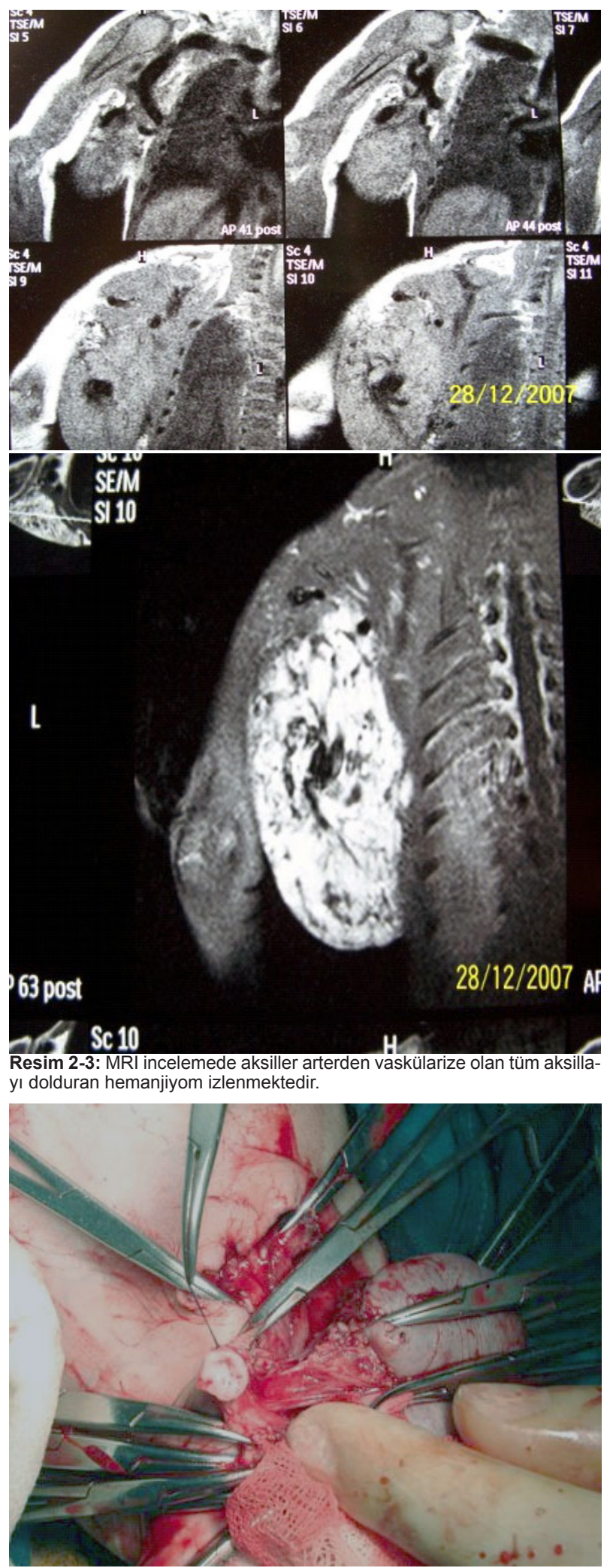

Resim 4: Aksiller arterden hemanjiyoma gelen damar bağlandıktan sonra çapının ne kadar geniş olduğu görülmektedir. 
Preoperatif hazırlıkları tamamlanan hasta ope-re edildi, ameliyatta aksiller arter dikkatlice ortaya konuldu, kitleye giden $1 \mathrm{~cm}$ çapındaki damar pedikülü bağlandı (Resim 4). Ameliyat sonras1 5. gününde aksiler hemovac dreni al1nan hasta taburcu edildi. Takiplerinde erken veya geç komplikasyon görülmedi. Bir yıl sonraki kontrollerinde nüks bulgusu izlenmedi.

\section{TARTIŞMA}

Yenidoğan döneminin sık karşılaşılan vasküler malformasyonlarından hemanjiyomlar genellikle takiple gerileyen iyi huylu lezyonlardır. İlk kez Lizter 1938'de hemanjiyomların kendiliğinden gerileyebildiğine dikkat çekmiştir (1-5). Regresyonun ilk belirtisi lezyonun parlak kırmızı renginin giderek matlaşmasıdır. Bununla beraber neonatal dönemdeki hemanjiyomlar takiplerinde önce büyüme eğiliminde olup aylar sonra gerilemeye başlarlar. Doğum sonrasinda giderek belirginleşen hemanjiyomlar genellikle ilk bir yaş büyüme eğilimindedir, boyutları küçük hemanjiyomlar 2-3 yıl içerisinde tamamen gerileyerek kaybolabilmektedir.

Hemanjiyomların biyolojik özelliklerinin iyi bilinmesi tedavinin planlanması için önemlidir. Hemanjiyomlar metastaz yapmadıklarından neoplazm olarak kabul edilmezler ve hamartom grubu altında incelenirler (1-5). Periferik kan damarlarının embrionik mezoderm içerisindeki hatalı gelișimi sonucu olușurlar. Aslında bu gelişim bir tümörün neovaskülarizasyon sürecinden farklı değildir. Her iki durumda da anjiogenetik faktörler rol oynamaktadır (1-5).

Tedaviye yaklaşımda takip, sklerozan tedavi veya cerrahi seçimi titizlikle değerlendirilmelidir. Konservatif tedaviye yanit vermeyen trombositopeni, kanama diatezi, anemi ve yetmezlik bulguları oluşturan $4 \mathrm{~cm}$ 'den büyük, travmaya açık hemanjiyomlar geciktirilmeden eksize edilmelidirler (2-4). Konservatif tedaviye rağmen involusyon göstermeyen $4 \mathrm{~cm}$ 'den büyük, ekzofitik büyümüş, travmaya açık hemanjiyomların geciktirilmeden cerrahi yöntemlerle eksize edilmesi gereklidir (2-4). Erken dönemde yapılan eksizyonların gerek kozmetik sonuçları gerekse postoperatif komplikasyon sonuçları, geç cerrahi yapılmış olgulardan daha azdır. Literatür incelendiğinde özellikle bu tür lezyonlarda 4 aydan önce cerrahi eksizyon önerilmektedir.

En sik yerleşim yeri olan baş ve boyun hemanjiyomlarının erken dönem cerrahi sonrasi kozmetik ve post-operatif komplikasyon açısından sonuçlarının daha iyi olduğu belirtilmektedir (3).
Ayrıca yenidoğan cildinin daha elastik oluşunun yara iyileşmesini kolaylaştırdığ 1 ifade edilmektedir (3). Cerrahi yöntemler arasında lentiküler insizyon ile yaklașılabileceği gibi sirküler insizyon ve purse string kapama ile de kozmetik sonuçların daha iyi olduğunu ifade eden gruplar vardır (4). Bizim olgumuzda da lezyonun çok büyük olması ve travmaya açık bir lezyon olması nedeni ile erken dönemde cerrahi uygulandi.

Olgumuzda hemanjiyom doğum anında yaklaşı $10 \mathrm{~cm}$ çapında oldukça geniş olması ve büyümeye başlaması nedeniyle; bir yaşına kadar çok fazla büyüyebileceği, trombositopeni ve kanama gibi komplikasyonlara yol açabileceği ve boyutlarının doğum anında dahi çok büyük olması nedeniyle regrese olamayacağı tarafımızca öngörüldü ve olası komplikasyonları önlemek için erken dönemde ameliyat edilmesine karar verildi.

Sonuç olarak, yenidoğan hemanjiyomları genellikle takiple gerileyebilen lezyonlar olmakla beraber; doğum anında mevcut 4 $\mathrm{cm}$ üzerindeki ekzofitik hemanjiyomlar, olas1 komplikasyonları azaltmak için erken postnatal dönemde opere edilmelidirler.

\section{KA Y N A KL A R}

1. Low DW. Hemangiomas and Vascular Malformations. Sem Ped Surg. 1994; 3 (2) : 40-61.

2. Santecchia L, Francesca Bianciardi Valassina $M$, Maggiulli F, Spuntarelli G, De Vito R, Zama M. Early surgical excision of giant congenital hemangiomas of the scalp in newborns: clinical indications and reconstructive aspects. J Cutan Med Surg. 2013; 17(2):106-113.

3. Spector JA, Blei F, Zide BM. Early surgical intervention for proliferating hemangiomas of the scalp: Indications and outcomes. Plast Reconstr Surg. 2008;122(2): 457-462.

4. Wu JK, Rohde CH. Purse-string closure of hemangiomas: Early results of a follow-up study. Ann Plast Surg. 2009; 62(5): 581-585.

5. Amir J, Metzker A, Krikler MB, Reisner SH. Strawberry Hemangioma In Preterm Infants. Pediatr Dermatol. 1986; 3: 331-332. 